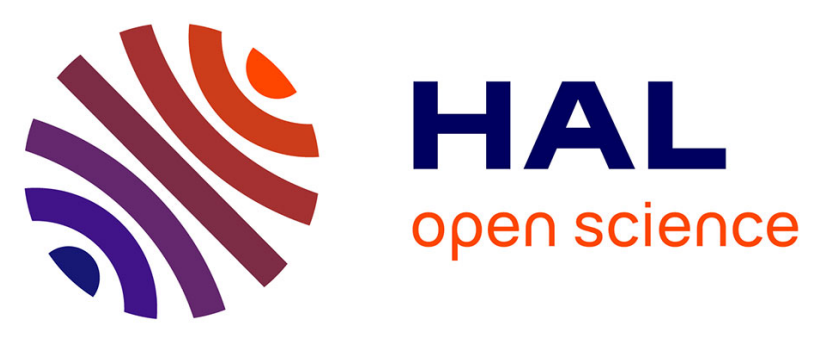

\title{
Experimental Demonstration of mid-IR Octave Spanning Supercontinuum Generation in Low Loss Silicon-Germanium Waveguide
}

Milan Sinobad, Pan Ma, Barry Luther-Davies, Stephen Madden, David J. Moss, Regis Orobtchouk, Salim Boutami, Jean-Michel Hartmann, Jean-Marc Fedeli, Christelle Monat, et al.

\section{To cite this version:}

Milan Sinobad, Pan Ma, Barry Luther-Davies, Stephen Madden, David J. Moss, et al.. Experimental Demonstration of mid-IR Octave Spanning Supercontinuum Generation in Low Loss SiliconGermanium Waveguide. Optical Fiber Communication Conference, Mar 2018, San Diego, United States. pp.M2J.3, 10.1364/OFC.2018.M2J.3 . hal-02006468

\section{HAL Id: hal-02006468 https://hal.science/hal-02006468}

Submitted on 12 Sep 2021

HAL is a multi-disciplinary open access archive for the deposit and dissemination of scientific research documents, whether they are published or not. The documents may come from teaching and research institutions in France or abroad, or from public or private research centers.
L'archive ouverte pluridisciplinaire HAL, est destinée au dépôt et à la diffusion de documents scientifiques de niveau recherche, publiés ou non, émanant des établissements d'enseignement et de recherche français ou étrangers, des laboratoires publics ou privés. 


\title{
Experimental Demonstration of mid-IR Octave Spanning Supercontinuum Generation in Low Loss Silicon Germanium Waveguide
}

\author{
Milan Sinobad ${ }^{1,2, *}$, Pan Ma $^{3}$, Barry Luther-Davies ${ }^{3}$, Stephen Madden ${ }^{3}$, David J. Moss ${ }^{4}$, Regis Orobtchouk ${ }^{1}$, \\ Salim Boutami ${ }^{5}$, Jean-Michel Hartmann ${ }^{5}$ ， Jean-Marc Fedeli ${ }^{5}$, Christelle Monat ${ }^{1}$, Christian Grillet ${ }^{1}$ \\ 1. Université de Lyon, Institut des Nanotechnologies de Lyon (INL), 69131 Ecully, France \\ 2. School of Electrical and Computer Engineering, RMIT University, Melbourne, Australia \\ 3. CUDOS, Laser Physics Centre, Australian National University, Canberra, ACT 0100, Australia \\ 4. Centre for Microphotonics, Swinburne University of Technology, Hawthorn, VIC 3122, Australia \\ 5. CEA-Leti, MINATEC Campus, 17 rue des Martyrs, 38054 Grenoble Cedex 9, France \\ Authore-mail address: s3524959@student.rmit.edu.au
}

\begin{abstract}
We report supercontinuum extending from 3 to $6 \mu \mathrm{m}$ generated in $\mathrm{Si} 0.6 \mathrm{Ge} 0.4 / \mathrm{Si}$ waveguide pumping with $\sim 200 \mathrm{fs}$ pulses at $4.15 \mu \mathrm{m}$. Experimentally measured low propagation loss $(0.4 \mathrm{~dB} / \mathrm{cm}$ in range $3.8-5.0 \mu \mathrm{m})$ and dispersion engineering waveguide allowed us achieving $\sim 5 \mathrm{~mW}$ useful average power.

OCIS codes: (130.0130) Integrated optics; (190.0190) Nonlinear optics; (320.0320) Ultrafast optics.
\end{abstract}

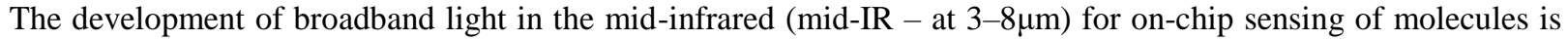
attracting growing interest. Main atmospheric gases and molecules that are important for our health and security have fundamental absorption lines in the mid-IR. In order to achieve low-cost and large-scale fabrication of compact devices for on-chip sensing, it is of special interest to find efficient group IV based integrated platforms exploiting mature CMOS fabrication processes [1,2]. A key building block is a stable and broadband light source with adequate output power. Supercontinuum generation sources represent an attractive approach and these have been already demonstrated on a variety of integrated platforms such as silicon-on-insulator, silicon nitride-on-insulator and silicon germanium-on-insulator [3-7]. However, to date this has largely been limited to wavelengths less than $3.5 \mu \mathrm{m}$ mainly due to the absorption in the silica substrate. Subsequently, supercontinuum generation at wavelengths as long as $6 \mu \mathrm{m}$ was reported on silicon-on-sapphire [8], but with a limited average output power due to strong nonlinear loss and absorption beyond $6 \mu \mathrm{m}$ of the sapphire substrate. Recently, silicon-germanium (SiGe) alloys, have emerged as an attractive alternative platform for mid-IR photonics [9-11], with transparency potentially extending up to $15 \mu \mathrm{m}$ depending on the Ge content [12].
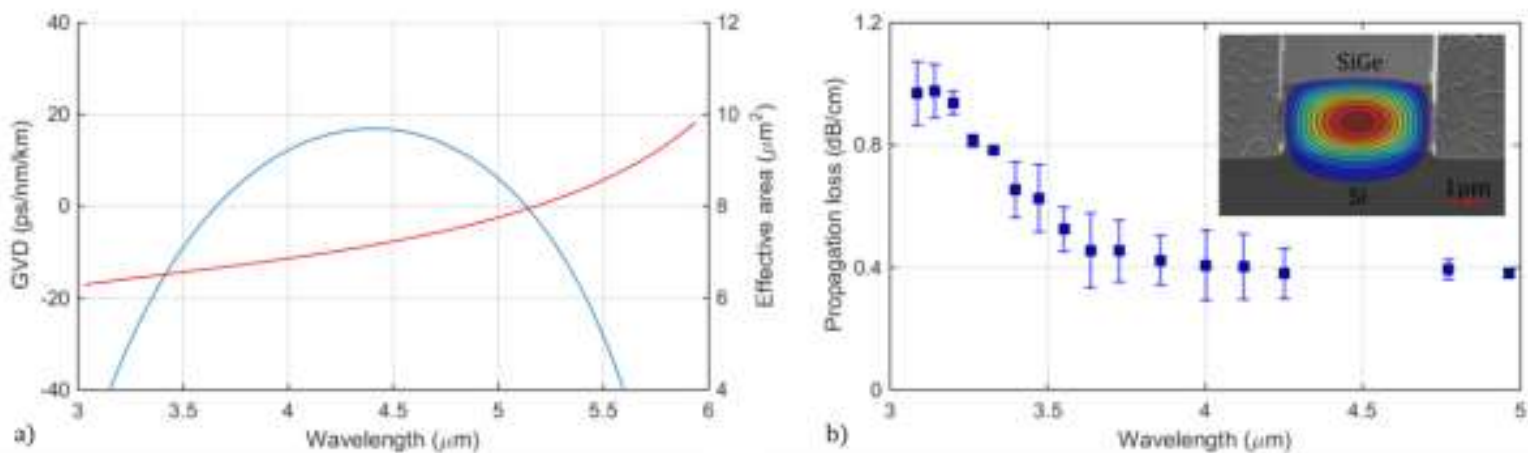

Figure 1 a) Calculated TE mode group velocity dispersion (GVD) blue and effective area mode red, b) Measured propagation loss versus signal wavelength with TE mode profile superimposed to the SEM image of the waveguide

In this work we report octave spanning SCG in the mid-IR from 2.95 to $6.0 \mu \mathrm{m}$ with a useful average power of $\sim 5 \mathrm{~mW}$ from a dispersion-engineered low-loss "air clad" Si0.6Ge0.4 waveguide. The waveguide consisted of a $2.7 \mu \mathrm{m}$ thick Si $.6 \mathrm{Ge} 0.4$ ridge $4.25 \mu \mathrm{m}$ wide on a silicon substrate. Our waveguide was engineered to have single-mode operation in the anomalous dispersion regime across a wide band with low effective area and strong mode confinement ( $\sim 96 \%$ at $4 \mu \mathrm{m})$ (figure 1a). As can be seen from the field distribution of the TE mode at $4 \mu \mathrm{m}$ (inset of figure $1 \mathrm{~b}$ ) this geometry also has the benefit of improving the mode confinement, thereby reducing the contribution from surface roughness to the loss. The measured propagation loss is shown in fig $1 \mathrm{~b}$, showing a loss as low as $0.4 \mathrm{~dB} / \mathrm{cm}$ in the broad range from 3.8 to $5 \mu \mathrm{m}$. Although being air-clad, these losses are the lowest measured so far in waveguides at mid-infrared wavelengths. Supercontinuum generation was then achieved by pumping the 
waveguide with $\approx 200 \mathrm{fs}$ TE polarized pulses from a mid-infrared MIROPA-fs optical parametric amplifier at a repetition rate of $63 \mathrm{MHz}$. Using a $7 \mathrm{~cm}$ long waveguide pumped at $4.15 \mu \mathrm{m}$ in the anomalous dispersion regime we obtained the spectra shown in Fig 2a for coupled average pump powers from $0.4 \mathrm{~mW}$ to $16 \mathrm{~mW}$.
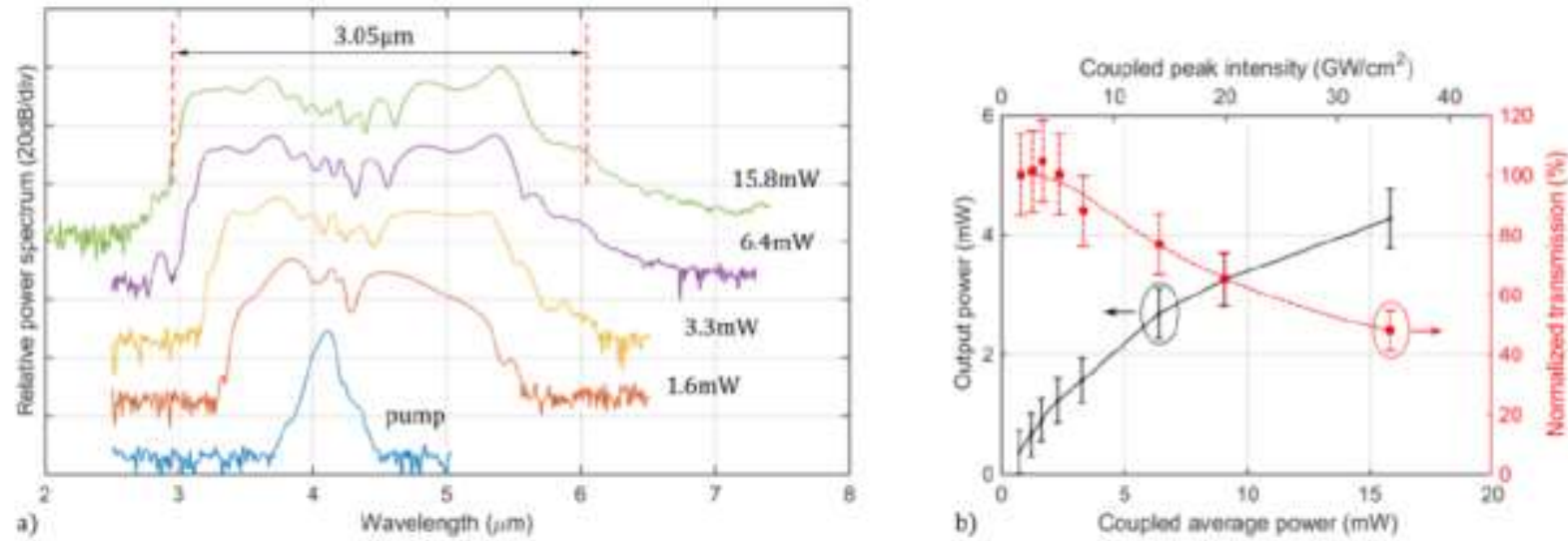

Figure 2 a) Output spectra measured at different coupled power, b) Measured output power versus coupled power (black) and normalized nonlinear transmission versus coupled peak intensity (red)

An octave-spanning supercontinuum spectrum with a $3.05 \mu \mathrm{m}$ bandwidth $(2.95-6.0 \mu \mathrm{m})$ at the $-30 \mathrm{~dB}$ level was achieved with $15.8 \mathrm{~mW}$ coupled average pump power $\left(\sim 35 \mathrm{GW} / \mathrm{cm}_{2}\right.$ coupled peak intensity). The long wavelength limit was not a result of material absorption but rather was associated with the cut-off of the fundamental mode (around $6.5 \mu \mathrm{m}$ ), as induced by the asymmetric waveguide design. Therefore, in principle, this can be extended by using a different geometry. Compared with previous results $[9,10]$, the lower propagation losses achieved here enabled us to generate supercontinuum at a much reduced pump intensity, thereby limiting the impact of high-order nonlinear absorption (Fig 2b). This translates into an increased supercontinuum average output power of 4-6mW. We also present normalized nonlinear transmission measurements, shown on figure $2 \mathrm{~b}$. In contrast to the results reported on silicon waveguides $[8,11]$, where a strong saturation $(\sim 10 \%)$ of the transmission occurred at $10 \mathrm{GW} / \mathrm{cm}_{2}$ coupled peak pump intensity, in our case we observe more than $80 \%$ of normalized transmission at this intensity and more than $40 \%$ at highest intensity levels. In summary, we report the first supercontinuum generation from a silicon germanium-on-silicon platform in the actual mid-IR wavelength, where most molecules have relevant fingerprints. The generated average mid-IR power exceeds that produced so far by other Si-based platforms. This establishes silicon germanium-on-silicon as a promising platform for integrated nonlinear photonics in mid-IR, with the potential to extend the operating range beyond $8 \mu \mathrm{m}$.

Acknowledgments: Agence Nationale de la Recherche (ANR) MIRSiCOMB (ANR-17-CE24-0028), European ERC grant GRAPHICS (648546); We acknowledge the support of the LIA ALPhFA.

\section{References}

[1] R. Soref, "Mid-infrared photonics in silicon and germanium," Nature Photonics, vol. 4, pp. 495-497, 2010.

[2] L. Zhang, A. M. Agarwal, L. C. Kimerling, and J. Michel, "Nonlinear group IV photonics based on silicon and germanium: from nearinfrared to mid-infrared," Nanophotonics, vol. 3, pp. 247-268, 2014.

[3] R. K. W. Lau, M. R. E. Lamont, A. G. Griffith, Y. Okawachi, M. Lipson, and A. L. Gaeta, "Octave-spanning mid-infrared supercontinuum generation in silicon nanowaveguides," Optics letters, vol. 39, pp. 4518-4521, 2014.

[4] J. M. Chavez Boggio, D. Bodenmüller, T. Fremberg, R. Haynes, M. M. Roth, R. Eisermann, et al., "Dispersion engineered silicon nitride waveguides by geometrical and refractive-index optimization," JOSA B, vol. 31, pp. 2846-2857, 2014.

[5] A. R. Johnson, A. S. Mayer, A. Klenner, K. Luke, E. S. Lamb, M. R. Lamont, et al., "Octave-spanning coherent supercontinuum generation in a silicon nitride waveguide," Opt Lett, vol. 40, pp. 5117-20, Nov 012015.

[6] M. A. Ettabib, L. Xu, A. Bogris, A. Kapsalis, M. Belal, E. Lorent, et al., "Broadband telecom to mid-infrared supercontinuum generation in a dispersion-engineered silicon germanium waveguide," Optics letters, vol. 40, pp. 4118-4121, 2015.

[7] B. Kuyken, T. Ideguchi, S. Holzner, M. Yan, T. W. Hansch, J. Van Campenhout, et al., "An octave-spanning mid-infrared frequency comb generated in a silicon nanophotonic wire waveguide," Nat Commun, vol. 6, p. 6310, Feb 202015.

[8] N. Singh, D. D. Hudson, Y. Yu, C. Grillet, S. D. Jackson, A. Casas-Bedoya, et al., "Midinfrared supercontinuum generation from 2 to 6 um in a silicon nanowire," Optica, vol. 2, pp. 797-802, 2015.

[9] L. Carletti, P. Ma, Y. Yu, B. Luther-Davies, D. Hudson, C. Monat, et al., "Nonlinear optical response of low loss silicon germanium waveguides in the mid-infrared," Optics Express, vol. 23, pp. 8261-8271, Apr 2015.

[10] L. Carletti, M. Sinobad, P. Ma, Y. Yu, D. Allioux, R. Orobtchouk, et al., "Mid-infrared nonlinear optical response of Si-Ge waveguides with ultra-short optical pulses," Opt Express, vol. 23, pp. 32202-14, Dec 142015.

[11] X. Gai, Y. Yu, B. Kuyken, P. Ma, S. J. Madden, J. Campenhout, et al., "Nonlinear absorption and refraction in crystalline silicon in the midinfrared," Laser \& Photonics Reviews, vol. 7, pp. 1054-1064, 2013.

[12] N. K. Hon, R. Soref, and B. Jalali, "The third-order nonlinear optical coefficients of Si, Ge, and Si1- xGex in the midwave and longwave infrared," Journal of Applied Physics, vol. 110, pp. 11301-11301, 2011. 